\title{
Prevención de riesgos laborales entre las personas con discapacidad intelectual en los centros especiales de empleo
}

\author{
Occupational Risk Prevention among Intellectually \\ Disabled People in Special Employment Centers
}

\author{
Milagros Paredes Gascón \\ Sociedad de Prevención de Fraternidad Muprespa \\ Matilde Fernández-Cid Enríquez. \\ Universidad Complutense de Madrid \\ choska@ccee.ucm.es \\ Ma Josefa Ruiz Figueroa. \\ Ministerio de Sanidad, Política Social e Igualdad \\ mruizf@mspsi.es
}

Recibido: 05/05/2011

Revisado: 17/10/2011

Aceptado: 28/11/2011

Disponible on line: 15/02/2012

\section{Resumen}

Este artículo presenta, esquemáticamente, el proceso de trabajo y algunos de los principales resultados de la investigación «Necesidades de formación en prevención de riesgos laborales para las personas con discapacidad intelectual en centros especiales de empleo». Interesaba, principalmente, analizar el lugar ocupado por la prevención de riesgos laborales en el ámbito del empleo protegido. Para ello se realizó un estudio transversal en tres centros especiales de empleo de una asociación pro personas con discapacidad intelectual de Madrid. El abordaje técnico contempló el análisis de fuentes secundarias, la observación directa y la realización de entrevistas abiertas (con los diversos agentes intervinientes: directores, psicólogos y preparadores laborales, técnicos de Prevención de riesgos laborales, encargados y empleados con discapacidad).

Los resultados muestran que la formación en Prevención de Riesgos se valora en muchos casos como insuficiente por los propios trabajadores, quienes, por otro lado, coinciden en una baja percepción del riesgo laboral que ellos mismos atribuyen y correlacionan con la limitada cualificación de sus tareas. En algunos casos, los entrevistados refieren que es la propia Organización del Centro de trabajo donde estos trabajadores con discapacidad prestan sus servicios, la que impide la correcta aplicación de sus conocimientos en Prevención de riesgos laborales. En un contexto general en el que la prevención de riesgos laborales se manifiesta como claramente mejorable, concluimos subrayando la necesidad de compromiso de las diferentes partes implicadas en el proceso de integración laboral de este colectivo, a fin de vincular la formación adaptada con el conjunto de la organización de trabajo.

Palabras clave: centros especiales de empleo, Prevención de riesgos laborales, Formación, Discapacidad Intelectual.

\begin{abstract}
This article summarizes the working process and some of the main results of the research entitled "Training Needs in Occupational Risk Prevention for Intellectually Disabled Persons in Special Employment Centers.” The main interest is to analyze the importance of occupational risk prevention in protected work environments. Thus, we developed and implemented a cross-sectional study in three special employment centers of a non-profit ProIntellectually Disabled Persons Association in Madrid. The methodology included analysis of secondary sources, direct observation and non-structured interviews (with various stakeholders: directors, psychologists, work trainers, risk-prevention technicians, managers and disabled employees).

The results show that occupational risk prevention training is graded as unsatisfactory by the workers, who also agree on their perception of the occupational risk as being low, which they attribute and correlate to the limited skill level required for their tasks. In some cases, interviewees indicate that it is the organization itself of the center where these disabled people provide their services which prevents the correct application of their knowledge of occupational risk prevention. The need for commitment on the part of those concerned in the
\end{abstract}


process of labor integration of this group is emphasized, in order to tie in adaptive training with the overall organization of the work.

Keywords: Special Employment Centers, Occupational risk prevention, Training, Intellectual disability.

Referencia normalizada: Paredes Gascón, M., Fernández-Cid Fernández M. \& Ruiz Figueroa, M. J. (2012): «Prevención de riesgos laborales entre las personas con discapacidad intelectual en los centros especiales de empleo». Cuadernos de Trabajo Social, 25(1): 249-260.

Sumario: 1. Las personas con discapacidad y el trabajo. 2. La prevención de riesgos laborales en los centros especiales de empleo. 3. Investigar la formación en prevención en centros especiales de empleo. 4. Algunas conclusiones. 5. Referencias bibliográficas.

\section{Las personas con discapacidad y el tra- bajo}

La Organización Mundial de la Salud, en su Clasificación Internacional del Funcionamiento de 2001, presenta la discapacidad como el efecto, determinado por el entorno, de una deficiencia que, al interactuar con otros factores en un contexto social específico, puede hacer que un individuo experimente una desventaja indebida en su vida personal, social o profesional.

Este planteamiento, vigente en nuestros días, ha supuesto una revolución en la forma de entender la discapacidad, al pasar de un modelo asistencial a un modelo funcional, de un modelo médico en el que los aspectos puramente sanitarios y asistenciales están acompañados de consideraciones de tipo caritativo, a un modelo todavía en evolución que, desde una perspectiva bio-psico-social, contempla tanto a las personas con deficiencias como las barreras contextuales existentes. Un modelo muy atento a la aplicación de derechos humanos, que coloca el acento en la igualdad de oportunidades y en la no discriminación, y en el que la persona es titular de derechos en su condición de ciudadana, tenga o no discapacidad (O.M.S., 2001).

En este sentido, en los últimos años se han alcanzado acuerdos, entre diversos poderes públicos intervinientes y ámbitos organizativos, para el desarrollo de tratados, declaraciones, normativas, estrategias y acciones legislativas, que tienen como objetivo explícito facilitar la integración de las personas con discapacidad.

En diciembre de 2006 fue aprobada por Naciones Unidas la Convención Internacional sobre los derechos de las personas con discapacidad y su protocolo facultativo. Se trata del primer instrumento amplio de derechos humanos elaborado en el siglo XXI para este colectivo y la primera Convención de Derechos Humanos que se abre a la firma de las organizaciones regionales de integración. Señala un cambio paradigmático del enfoque y las actitudes respecto de las personas con discapacidad. Esta Convención se concibió como un instrumento de derechos humanos con una dimensión explícita de desarrollo social. Su propósito es promover, proteger y asegurar el goce pleno y en condiciones de igualdad, de los derechos humanos - entre ellos, el derecho al trabajo- y las libertades fundamentales para todas las personas con discapacidad. En su artículo 27 destaca la necesidad, en el ámbito laboral, de «prohibir la discriminación por motivos de discapacidad»; «proteger los derechos de las personas con discapacidad, en pie de igualdad», el «acceso efectivo a programas» y «asegurar que se realicen ajustes razonables para las personas con discapacidad en el lugar de trabajo» ${ }^{1}$.

España ratificó esta Convención en diciembre de 2007, coincidiendo con el Día internacional de las personas con discapacidad y queda, de esta manera, obligada a observarla, cumplirla y hacer que se cumpla en todas sus

\footnotetext{
${ }^{1}$ Asamblea General de las Naciones Unidas, Convención Internacional sobre los derechos de las personas con discapacidad. Nueva York, 13 de diciembre de 2006. http://www.un.org/esa/socdev/enable.
} 
partes, según los criterios que rigen el derecho internacional ${ }^{2}$.

La integración laboral sigue siendo, para la mayoría de la población, la vía principal de acceso a la satisfacción de necesidades físicas, psicológicas y sociales, y supone el factor determinante en el tránsito de la dependencia a la independencia familiar (Colectivo IOÈ, 2003).

La última Encuesta sobre Discapacidades, Autonomía Personal y Situaciones de Dependencia (EDAD), realizada en España en 2008, estima en 3.800.000 el número de personas con discapacidad, lo que supone un 8,5 por ciento de la población española ${ }^{3}$. En 3.300.000 millones de hogares españoles (20 por ciento del total de hogares) reside, al menos, una persona con discapacidad; en más de medio millón de hogares viven dos o más personas con discapacidad. En 2008, había un total de 1.480.000 personas con discapacidad en edad de trabajar (16-64 años), de ellas, un 28,3 por ciento trabajaba. Por sexos, el porcentaje de mujeres que trabajaba era casi 10 puntos porcentuales inferior al de los hombres. Sin embargo, en la mayoría de los casos las discapacidades representan limitaciones que no tienen por qué impedir una integración laboral normalizada.

Si atendemos al tipo de discapacidad, las personas afectadas por deficiencias sensoriales son quienes han logrado mayor participación en el mercado de trabajo remunerado, especialmente las personas con discapacidad auditiva; les siguen, a considerable distancia, las personas empleadas con discapacidad física y, por último, las que presentan algún tipo de disca- pacidad de naturaleza psíquica y las personas con discapacidades mixtas ${ }^{4}$.

Algunas de las causas que podrían explicar la escasez de acceso de las personas con discapacidad al mercado de trabajo, podrían ser las siguientes ${ }^{5}$ :

- En lo que respecta al demandante, en aquellas discapacidades de tipo congénito o producidas en la edad infantil, la opción por vías «especiales» de gestión de la discapacidad en todos los ámbitos de socialización del individuo (familiar, escolar, social), sitúa a la persona con discapacidad en entornos e itinerarios que no favorecen la integración futura en el mundo laboral, por encontrarse impregnados de una inercia paternalista y proteccionista que evita, por regla general, la aproximación a entornos normalizados.

- Uno de los motivos que se vienen considerando como condicionante fundamental para la incorporación laboral de las personas con discapacidad, es su escasa formación académica y profesional. En las últimas encuestas se constatan cambios positivos en las generaciones recientes, pero todavía las personas con discapacidad adolecen de carencias en el nivel de estudios que se reflejan en la población activa y que marcan en mayor medida a las generaciones más maduras y especialmente del sexo femenino. La integración laboral no se alcanzará si previamente no se ha conseguido una integración escolar real, ejemplo de lo cual queda de manifiesto en el hecho de que los afectados por deficiencias sensoriales, que tienen las tasas de formación más elevadas, tam-

\footnotetext{
${ }^{2}$ Ratificación por el Reino de España de la Convención de la ONU. BOE de 21 de abril de 2008.

${ }^{3}$ Las más frecuentes de estas limitaciones son las que tienen su origen en deficiencias físicas (afecciones del sistema locomotor, sistema nervioso y órganos internos), y representan aproximadamente la mitad del total de las discapacidades; en segundo lugar, las deficiencias sensoriales, que afectan a la vista, al oído y al habla (un tercio de las discapacidades); y, en tercer lugar, las deficiencias psíquicas, que incluyen el retraso mental, las demencias y otros trastornos psicológicos.

${ }^{4}$ Encuesta sobre Discapacidad, Autonomía Personal y Situaciones de Dependencia (EDAD 2008). Instituto Nacional de Estadística, Ministerio de Sanidad y Política Social.

5 Teniendo en cuenta los contenidos de las siguientes fuentes oficiales:

- Encuesta sobre Discapacidades, Deficiencias y Estados de Salud. INE, Fundación ONCE y Ministerio de Trabajo y Asuntos Sociales; Madrid, 2000.

- Encuesta sobre Discapacidad, Autonomía Personal y Situaciones de Dependencia (EDAD 2008); Instituto Nacional de Estadística, Ministerio de Sanidad y Política Social.

- Estrategia global de acción para el empleo de personas con discapacidad 2008-2012, Ministerio de Educación, Política Social y Deporte, Madrid, 2008.
} 
bién son quienes han logrado mayores tasas de integración en el trabajo remunerado.

- Desde el punto de vista del empleador, muchos empresarios evitan la contratación de personas con discapacidad por el desconocimiento de los distintos tipos de discapacidad y sus potenciales, y la consiguiente (y basada en ideas estereotipadas y prejuiciosas) atribución de limitaciones en el desempeño laboral por motivos de supuesta escasa cualificación y polivalencia, o su dificultad de adaptación a las nuevas tecnologías y a ritmos de trabajo exigentes, etc. Se expresan también justificaciones de tipo económico como las exigencias de realizar adaptaciones de los puestos y entornos de trabajo que favorezcan la accesibilidad, la estructura actual de las ayudas y subvenciones a la contratación, la inexistencia en definitiva de una igualdad de trato, que se manifiesta por ejemplo en el insuficiente cumplimiento de la obligación de respetar la cuota de reserva ${ }^{6}$ para personas con discapacidad, entre otras cuestiones.

- Otros de los motivos que se aducen como causantes del reducido porcentaje de ocupación entre la población con discapacidad es que: las barreras con las que se topan las personas con discapacidad, los bajos salarios, las prestaciones económicas y las ayudas que desincentivan la inserción laboral, el parco desarrollo de políticas activas de empleo, la escasa aplicación adecuada de contratos de trabajo a tiempo parcial y de fórmulas flexibles de organización del tiempo de trabajo, e incluso - por incluir asimismo alguna de las «barreras internas»- la propia percepción negativa que tienen algunas personas con discapacidad del empleo.

Partimos, pues, de la constatación de la necesidad de estudiar el proceso de integración, laboral en este caso, de las personas con discapacidad intelectual, ya que la mayoría de ellas no ha entrado en el mercado laboral, lo que significa que no tiene opción a un empleo remunerado. Sin embargo el propio concepto de integración alude a la participación activa en entornos ordinarios, en los que la mayoría de las personas desarrollan sus roles habituales (Alonso Seco, 1997).

En este sentido abarcador y en el marco del modelo socio-económico en el que actualmente se inscribe, la importancia del empleo va más allá de su valor económico (en el sentido más restrictivo), y cobra especial relevancia su contribución a la conformación de identidad y a la dimensión social de la persona; todo ello derivaría, asimismo, en un efecto muy querido por la psicología hegemónica actual: la mejora de la autoestima (Fundación Mapfre Medicina, 1992). El acceso al trabajo se presenta como la más real y legitimadora vía para alcanzar la autonomía personal (para dejar de ser, socialmente, discapacitado). Desde esta perspectiva y en este contexto, se entiende el empleo como una actividad humana destinada a satisfacer necesidades físicas, psicológicas y sociales, que lo transforma también en una dimensión central para la mejora de la salud, en la acepción más amplia del término.

\section{La prevención de riesgos laborales en los centros especiales de empleo}

Centrados, pues, en un marco de Derechos de las personas con discapacidad, el ejercicio del Derecho al Trabajo, debe reunir por imperativo legal unas condiciones de Seguridad y Salud en el Trabajo, para las que se han habilitado ayudas técnicas y adaptaciones en el entorno de trabajo, necesarias para compensar y/o vencer las limitaciones funcionales y las condiciones contextuales adversas. En este sentido, el considerar las características y los vínculos del trabajador/a con el puesto de trabajo es clave para la adaptación, derecho fundamental para las personas con discapacidad (Del Corral Martín, 2004). La Ley 31/1995, de Prevención de riesgos laborales, dedica el artículo 25 a la Protección de trabajadores especialmente sensibles a determinados riesgos, que en su apartado 1 declara: El empresario garantizará de manera específica la protección de los trabaja-

${ }^{6}$ El artículo 38.1 de la Ley de Integración Social de los Minusválidos (LISMI, BOE de 13 de abril de1982) establecía una reserva del $2 \%$ de puestos de trabajo para personas con discapacidad, obligatoria para todas las empresas, públicas o privadas. La Ley 53/2003, sobre Empleo público para discapacitados (BOE de 11 de diciembre de 2003) actualiza algunos contenidos de la LISMI y establece en un 5\% esa cuota de reserva para las empresas públicas. 
dores que, por sus propias características personales o estado biológico conocido, incluidos aquellos que tengan reconocida la situación de discapacidad física, psíquica o sensorial, sean especialmente sensibles a los riesgos derivados del trabajo ${ }^{7}$.

Algunos autores se han preocupado de analizar esta Ley y de seguir su nivel de cumplimiento desde su aprobación. En las páginas de esta misma Revista ( $\mathrm{n}^{\circ}$ 60, «Estado, política y salud de los trabajadores España, 18832007»), Juan José Castillo y Pablo López Calle recorren el proceso de constitución del sistema de prevención en España, y sitúan las políticas de riesgos laborales en el contexto de los sistemas productivos en que funcionan, y que les da sentido (Castillo y López, 2007). Pues bien, además de analizar los datos de (muy alta) siniestralidad laboral en España, explican su contexto de producción: «Un modelo de producción de vía baja (trabajo descualificado, unido a bajos salarios), indica que los beneficios empresariales se basan en la intensificación del trabajo y no en el incremento de la productividad del trabajo. España... muestra una progresiva disminución de la productividad, mientras que la siniestralidad actualmente dobla la media... Estos datos remiten a la especialización productiva española en sectores que se caracterizan por exigir una menor cualificación, intensivos en trabajo manual y que ofrecen bajos salarios». Si este dato alude a la población trabajadora, en general, podemos presuponer una situación todavía más alarmante para colectivos cuya caracterización en términos de fuerza de trabajo pondera los mencionados rasgos (descualificación, trabajo manual intensivo).

La Prevención de riesgos laborales debería constituir una exigencia de primer orden para las empresas pero, a pesar del desarrollo normativo y procedimental que se ha producido en esta materia, la legislación vigente no aborda con suficiente amplitud entre otras cuestiones las peculiaridades de gestión de la prevención para los trabajadores con discapacidad, que - por su estado físico, biológico, psíqui- co...- pueden presentar dificultades especiales con unos riesgos específicos. Ello complica en gran medida el tratamiento de esta cuestión, especialmente por parte de las empresas de menor tamaño (Fundación ONCE, 2004).

Ciertamente, estas nuevas normativas tienden a encarecer la fuerza de trabajo si no se establecen subvenciones adecuadas o se garantiza a la empresa una mayor productividad, con lo que nos encontramos ante una importante paradoja de partida: existe una presión hacia el trabajo como vía de capacitación (reconocimiento de autonomía) pero las «personas con discapacidad» tienen limitado su acceso, tanto por las deficientes condiciones de los puestos de trabajo como por los escasos recursos económicos percibidos.

La formación en Prevención de riesgos laborales debe no sólo asegurar conocimientos para el correcto desempeño laboral, sino también facilitar las claves para reconocer que la actividad laboral reúna las condiciones de seguridad y salud exigidas. La Ley de Prevención de riesgos laborales, en su Artículo 19 dice textualmente (apartado 1): En cumplimiento del deber de protección, el empresario deberá garantizar que cada trabajador reciba una formación teórica y práctica, suficiente y adecuada, en materia preventiva... centrada especificamente en el puesto de trabajo o función de cada trabajador.

Los antecedentes encontrados en nuestro país respecto al desarrollo de Proyectos y Programas de Prevención de riesgos laborales dirigidos de forma específica a personas con discapacidad intelectual son escasos y, en su mayoría, diseñados por el movimiento asociativo, con el patrocinio de organismos públicos o empresas privadas, en el seno de sus políticas de acción social. Algunos ejemplos son el Proyecto «Adalid», en la C.A. de Castilla y León ${ }^{8}$, los Manuales de Prevención de riesgos laborales para personas con discapacidad intelectual, elaborados por FEAPS ${ }^{9}$ (Federación Estatal de Asociaciones a favor de personas con discapacidad Intelectual) o el Proyecto «Hazilan»" enmarcado en la Iniciativa Comunitaria

\footnotetext{
${ }^{7}$ Ley 31/1995, de prevención de riesgos laborales ( BOE de 10 de noviembre de 1995).

${ }^{8}$ http://www.feapscyl.org/adalid.htm.

${ }^{9}$ http://www.feapsmadrid.org/portal/web/menu/biblioteca/LF/index.htm.

${ }^{10} \mathrm{http}$ ://www.ehlabe.org/zabalan/web/home/index.php.
} 
«Equal», dirigido a la mejora de accesibilidad al uso de nuevas tecnologías.

Debido a que las fórmulas de empleo protegido son las que más peso tienen en nuestro país en el acceso de personas con discapacidad al empleo remunerado, el trabajo que presentamos se centra en uno de los modelos de empleo protegido más frecuentes: los centros especiales de empleo (CEE). La gestión administrativa de estos centros pertenece a las Comunidades Autónomas, aunque su titularidad suele estar vinculada a distintas Asociaciones. Están subvencionados por la Administración y gestionan empleo para personas con discapacidad (incluido en la Seguridad Social); el centro especial de empleo se constituye en figura de intermediación con la empresa. Sin embargo, hay que subrayar la baja cualificación (casi todos los puestos en la categoría «peones»), la escasez de expectativas de promoción profesional y la baja remuneración (la mayoría percibe el salario mínimo). En la muestra de trabajadores con discapacidad intelectual analizada (que, obviamente, no tiene ambición de representatividad estadística, pero sí de muestra significativa y de representación situacional), la mayoría son hombres, con deficiencias psíquicas de origen congénito o infantil y bajo nivel de cualificación escolar y profesional.

El número de plazas en los centros especiales de empleo ha experimentado un crecimiento importante, sin embargo pocas veces se consigue el objetivo de que sirva de trampolín para acceder al mercado de trabajo ordinario. Más bien, lo que se produce es un efecto «burbuja», que proporciona a los trabajadores y trabajadoras de estos centros un mayor sentimiento de seguridad, pero en un marco de «sobreprotección» que limita sus expectativas y eventuales posibilidades de promoción laboral autónoma: se evidencia aquí la paradoja de un «paternalismo» sin perspectiva real de constituir un paso de transición lo más breve posible hacia el «trabajo ordinario» (Colectivo IOĖ, 1998).

Nuestro interés se ha centrado en conocer, en la medida que sea posible, de qué manera se impregna en los centros especiales de empleo este impulso integrador y normalizador, que late en la actualidad en el discurso del conjunto de las políticas sociales y de empleo y atiende - también, pero de forma específica - a las condiciones de seguridad y salud para prevenir riesgos laborales. Se buscaba sobre todo una aproximación a la experiencia laboral de las personas con discapacidad intelectual que trabajan en centros especiales de empleo (opiniones, historia, motivaciones e inquietudes) y al proceso formativo de estos trabajadores, tanto a nivel de formación ocupacional como de formación en prevención de riesgos laborales.

\section{Investigar la formación en prevención en centros especiales de empleo}

El trabajo de investigación ha tomado como muestra tres centros especiales de empleo de la asociación Pro-Personas con discapacidad intelectual de Madrid, dedicados a actividades bien diferentes:

1. Catering integral (elaboración, envasado y transporte de alimentos) con 33 trabajadores.

2. Conservación y mantenimiento de bienes inmuebles: jardinería, limpieza, higienización, etc. Cuenta con unos 240 trabajadores entre los centros donde se da el servicio.

3. Imprenta, maquetación y manipulados, con 88 trabajadores.

La selección de esta muestra se ha realizado buscando acceder a cierta pluralidad de actividades, perfiles profesionales, entornos y lugares de trabajo, dispersión geográfica dentro de la Comunidad de Madrid, y exigencias en cuanto a nivel de autonomía del trabajador, y con un esquema empresarial en el que los centros tienen autonomía de dirección; pero, comparten estructuras organizativas como el Servicio de prevención de riesgos laborales o la Dirección de Recursos Humanos.

La población consultada abarca el conjunto de trabajadores en plantilla en dichos centros especiales de empleo: personas con discapacidad y relación contractual de carácter especial y profesionales con relación laboral ordinaria de las distintas áreas o secciones de la empresa y entre ellos los implicados en la gestión de la Prevención de riesgos laborales.

En concreto en esta investigación se ha aplicado preferentemente la técnica de entrevista abierta semiestructurada (aunque también la observación directa y la consulta de fuentes secundarias) — en el marco de la meto- 
dología cualitativa - con una selección de muestra estructural/estratégica que considera tanto los lugares funcionales y jerárquicos ocupados en la actividad laboral de los diversos agentes intervinientes como su condición de persona con o sin discapacidad. Como afirma Monnerot (Monnerot, 1952), la mejor prueba de que los hechos sociales no son cosasacontecimientos, comportamientos, que se dejen observar y medir desde fuera, sin considerar el sentido de la acción social, es que "su sentido cambia según el punto de vista de los diversos grupos cuyos antagonismos, en un momento dado, componen un equilibrio o un desequilibrio social, es decir un estado de sociedad». Los procesos vitales de la población con discapacidad intelectual participan plenamente de esa imposibilidad de «cosificación» que permitiría aprehenderlos como si de un objeto estático y ajeno al sujeto se tratara. Junto a innegables elementos denotados y connotados que posibilitan alguna definición de este proceso, se percibe un cúmulo de dimensiones simbólicas y referenciales, en función de los distintos grupos sociales que lo padecen, lo observan o pretenden actuar sobre el mismo. Nos situamos asimismo en un marco general de trabajo próximo a la etnometodología, en cuanto al uso que en esta disciplina se hace de las técnicas de observación participante y de los conocimientos del «sentido común» y la «vida cotidiana».

Se realizaron un total de 30 entrevistas a: responsable de Recursos humanos de la asociación, directores de centros especiales de empleo, psicólogas y preparadores laborales, delegados de prevención, técnico de Prevención de riesgos laborales, directores de Área, encargados, $\mathrm{y}$, de forma mayoritaria, trabajadores con discapacidad. Los resultados recogen sus experiencias y opiniones relativas a la formación e información acerca de los riesgos en sus trabajos, ya desde antes de la incorporación, pasando por su puesta en práctica en la actividad laboral y hasta apuntar expectativas para un posible desarrollo de futuro profesional.

Los/as preparadores laborales consultados destacan que la persona con discapacidad intelectual, que se incorpora a un puesto de trabajo, generalmente desconoce las exigencias y obligaciones propias del desempeño de una ac- tividad laboral. No existe educación laboral, en el sentido de que la información que se tiene del entorno laboral está inmersa en un proteccionismo aprendido ya desde la infancia.

Debería haber un paso desde el Centro Ocupacional al Centro especial de empleo, en el que se realizase una selección de perfiles profesionales y se preparase para trabajar, informando y dando la posibilidad de elección enfocada a puestos adecuados a cada sujeto. (Psicóloga preparadora laboral).

Sin embargo, son los encargados de integración laboral quienes a su vez afirman que la actitud de las personas con discapacidad intelectual (con excepciones) hace que, tras un corto periodo de tiempo de permanencia en el entorno laboral, esas iniciales carencias en conocimiento y en destrezas laborales sean superadas por la mayoría de los trabajadores cuando tienen los apoyos necesarios. Las dificultades de partida para el acceso al trabajo y las expectativas convocadas se muestran como motores que incentivan el sobreesfuerzo exigido, compensando el déficit inicial.

Estos profesionales implicados en el proceso de formación y seguimiento laboral del colectivo de personas con discapacidad intelectual han señalado que, tanto en su opinión como en la expresada por los propios contratadores, resultan muy positivos algunos rasgos comunes que caracterizan a los trabajadores con discapacidad intelectual: existe amplia coincidencia en afirmar que se trata de trabajadores que aceptan de buen grado las indicaciones y acatan las normas. Son, en general, responsables en su trabajo, meticulosos, con bajas tasas de absentismo y poca tendencia a desatender el puesto de trabajo. Toleran bien, en general, la monotonía de algunos trabajos como manipulados, en los que las rotaciones se producen en muchos casos cada dos o tres semanas.

Una vez adquirida esa cultura laboral y realizada la formación oportuna, su rendimiento ha sido valorado por muchos de los encargados como igual o, en algunos casos, superior al de otros trabajadores sin discapacidad. El desempeño de su trabajo cuestiona el prejuicio de aquellas empresas clientes que no prevén la obtención de un trabajo de calidad en el resultado. Dados estos prejuicios de partida, los encargados de preparación laboral reconocen es- 
tar sometidos a una presión mayor, al verse obligados a estar continuamente demostrando la competitividad que estos Centros de trabajo pueden ofrecer:

Tenemos la percepción de que se mira con lupa el trabajo, el control de calidad es más exhaustivo por prejuicio y luego el cliente se lleva la sorpresa de que con este personal se cometen menos errores que en una empresa normal (Encargado de industrias gráficas y delegado de prevención).

Consideran estos encargados de la preparación laboral, cuyo contacto con estos trabajadores con discapacidad intelectual es más intenso y diario, que la primera motivación de una persona con este tipo de discapacidad para trabajar es alcanzar la independencia económica, aunque también aluden a otros alicientes vinculados a su actividad laboral (realización personal, utilidad social, establecimiento de redes sociales, etc.).

La formación que imparten estos centros especiales de empleo en prevención de riesgos laborales es escasa. En el momento de realizar esta investigación, el Sistema de gestión de prevención se encontraba en desarrollo, y contaba como uno de sus objetivos la implantación a lo largo del 2009 de un calendario de formación en prevención de riesgos laborales. De esta manera, en la fecha de realización de este trabajo, la formación en este tipo de prevención consistía en la entrega de un manual de prevención de riesgos laborales elaborado por la Confederación española de organizaciones de las personas con discapacidad intelectual (FEAPS), adaptado en lectura fácil sobre la materia o área de trabajo concreta (limpieza, en el caso de los trabajadores de limpieza, en jardinería en el caso de trabajadores de jardinería, en manipulados con máquinas, en el caso de artes gráficas y manipulados), e información verbal sobre prevención de riesgos laborales al inicio del contrato. Los preparadores laborales realizan la entrega del manual, y aseguran que los trabajadores con discapacidad lo leen, ya sea porque lo hacen en común, en el puesto de trabajo, o porque lo llevan a su domicilio y luego se les pregunta sobre los contenidos, como forma de control.

El delegado de prevención opina que la formación en riesgos laborales es importante, y la mejor forma de impartirla sería con un método pedagógico eminentemente práctico, sin embargo, afirma que, por el momento, con la lectura del Manual de la Confederación española de organizaciones en favor de las personas con discapacidad intelectual y con las indicaciones verbales de sus superiores, el aspecto preventivo está cubierto. Estas dos observaciones resultan claramente contradictorias, lo que indica la desorientación y/o las barreras percibidas por parte de los propios responsables de prevención. A su modo de ver, los trabajadores están implicados en la prevención, conocen los riesgos laborales de sus puestos de trabajo y, cuando se introduce un nuevo procedimiento, se insiste en la comprensión de su ejecución y en el aprendizaje de los riegos que representa y cómo prevenirlos.

En el centro especial de empleo dedicado a catering existen algunos puestos de trabajo en los que los riesgos laborales exigen un trabajador formado específicamente, ya que se lleva a cabo un sistema de registro de incidencias que asegura que se tenga constancia y conocimiento del porqué se ha producido un error, y cómo evitarlo. Los trabajadores recibieron formación en manipulación de alimentos y un curso de prevención de cursos laborales impartido por dicha Confederación. Según la psicóloga del centro, la adaptación del curso a personas con discapacidad intelectual estuvo muy limitada, debido fundamentalmente a que no fue vinculado a la práctica y a que, por las características del personal de estos centros, se requiere un método didáctico práctico y en el puesto de trabajo a ser posible. Un encargado de Manipulados hacía hincapié en que en estos cursos se viesen las consecuencias negativas de cometer errores por no aplicar las medidas de prevención, o no emplear los equipos de protección individual.

En jardinería, los encargados opinan que los riesgos laborales se aprenden a identificar en la práctica, mediante pautas verbales, independientemente de la recepción y lectura del manual de prevención de riesgos en este campo o de la realización de cursos. Consideran que la formación en prevención de riesgos laborales debería ser eminentemente práctica, en grupos pequeños, y complementada con talleres de contenidos propios de la actividad (talleres de poda, riego, botánica, etc.), para atender 
a las demandas de los propios trabajadores en cuanto al interés en una ampliación de contenidos profesionales que enriquezcan y diversifiquen la actividad diaria.

En el área de jardinería, las personas con discapacidad entrevistadas tenían formación en esta materia antes de entrar en el centro especial de empleo (en escuela-taller, por cursos del INEM, o en módulos de garantía social), que incluía siempre algún contenido en prevención de riesgos laborales. La formación recibida en el centro especial de empleo consistió en la entrega del manual de prevención de riesgos en jardinería, a lo que se añade una formación, en formato de charlas, impartida por el técnico de prevención de riesgos laborales de la empresa. También declaran conocimientos básicos en primeros auxilios en lo referente a actuaciones en casos de cortes y heridas, y a quién acudir en caso de accidente de trabajo.

El conocimiento referido acerca de los riesgos en los trabajos de jardinería y de las medidas preventivas a adoptar en cada caso, es bastante completo. Sin embargo, pese a demostrar un buen conocimiento de su trabajo y la adquisición de buenas prácticas de prevención, algunos de los trabajadores con discapacidad consultados tienden a minimizar el riesgo en el trabajo que realizan ya que, dicen, se limita a tareas manuales simples, como barrer hojas con escoba de flejes, regar con manguera, limpiar y retirar malas hierbas, cavado, etc. No emplean ningún tipo de herramienta con motor, como motosierra, cortacésped, desbrozadora, ni hacen tareas de poda o aplicación de fitosanitarios. Por esta razón, aun reconociendo los muchos y variados riesgos que pueden conllevar las tareas de jardinería, coinciden en señalar que su trabajo, en la práctica, apenas los tiene y lo relacionan, en valoración negativa, con la escasez de iniciativa, la monotonía y la pobreza de contenidos.

Algunos trabajadores con discapacidad manifiestan una postura muy crítica y realista sobre el tema; por ejemplo, una trabajadora de limpieza en un colegio aseguraba no haber contado con la colaboración necesaria (incluso hablaba de resistencia por parte de los responsables de la organización) a la hora de querer aplicar en su trabajo sus conocimientos en prevención de riesgos laborales:
Yo lo intento cumplir, pero hay personas que no nos dejan cumplirlo. Limpiamos por la tarde con las persianas bajadas porque son a motor y la directora del colegio las deja bajadas para que no se rompan. Trabajamos sin ventilación, y nos tragamos todos los productos que usamos y lo que barremos. A mí me viene fatal porque tengo alergia al polvo. Cuando le explicamos esto a la directora no entra en razón.

En el centro especial de empleo que hemos consultado dedicado a catering integral, uno de los trabajadores con discapacidad entrevistados valora que el curso de prevención de riesgos laborales impartido por la empresa fue demasiado general y escasamente adaptado al perfil de los trabajadores con discapacidad intelectual. También echó en falta en ese curso de prevención de riesgos algunas nociones sobre primeros auxilios, a pesar de trabajar en un medio en el que es vital extremar los cuidados, por los utensilios que se manejan (máquinas cortadoras, cuchillos, fiambrera, picadora o selladora) y por el contacto con el fuego (se pregunta si sabrían qué hacer ante una quemadura o un corte profundo). En el curso de manipulador de alimentos y de prevención de riesgos laborales, que impartió la Confederación española de organizaciones de las personas con discapacidad intelectual, los trabajadores recibieron orientaciones sobre algunos riesgos asociados a las tareas de limpieza: información sobre los productos utilizados, las etiquetas de seguridad o las mezclas peligrosas.

Respecto a la realización de adaptaciones de los puestos de trabajo, los encargados y preparadoras laborales opinan de forma muy parecida, en el sentido de que la adaptación más necesaria y prácticamente única es la que hace referencia a la organización y los ritmos de trabajo y a la información sobre las tareas. En artes gráficas es donde mayores adaptaciones se han realizado, debido al imperativo que supuso el reglamento de máquinas con la entrada en vigor de la Ley de prevención de riesgos laborales, lo que provocó el cambio de algunos equipos de trabajo y máquinas que, o bien estaban obsoletas, o no tenían el marcado Centro especial y había que realizar cambios estructurales en los mecanismos de seguridad.

En el centro especial de empleo de manipulados las tareas que realizan los trabajadores con discapacidad son: manipulado de papel y 
cartón, montaje de piezas de ferretería, objetos de decoración de empaquetado en las campañas de Navidad, y otras actividades similares. El trabajo se realiza en cadena, y todos los entrevistados han manifestado poder sentarse en el momento que lo necesiten, aunque si la carga de trabajo es grande y el ritmo elevado, cosa que sucede en pocas ocasiones, tienen que permanecer de pie. La rotación de las tareas sucede cuando finalizan el encargo en que estén trabajando, lo cual puede ser cada dos semanas. En ese centro de trabajo existe maquinaria: guillotina, cosedora, retractiladora, etc., que sólo usan los profesionales o trabajadores sin discapacidad y los encargados. Algún trabajador con discapacidad puede, puntualmente, manejar alguna de las máquinas. Una opinión compartida entre trabajadores con discapacidad es que la monotonía resulta lo más molesto de su trabajo, y algunos manifiestan su deseo de acceder a formación para el empleo de máquinas y así poder hacer su trabajo más interesante. Conocen los riesgos ergonómicos de la manipulación manual de cargas en cuanto a la forma correcta de coger y manejar pesos, pero desconocen los derivados de los movimientos repetitivos de miembros superiores o de las posturas estáticas mantenidas.

El uso de equipos de protección individual (EPIs) es generalizado: guantes (para cocinar, limpieza, cortar), gorro, botas y ropa de trabajo. Además conocen de forma elemental el riesgo eléctrico y la forma de manipular enchufes, el uso de escaleras de mano, las precauciones ante suelos mojados, y en cuanto al riesgo ergonómico, saben cómo manipular cargas adecuadamente, aunque reconocen no siempre hacerlo en la práctica.

Veamos por su parte — como aporte complementario - la opinión tanto del técnico de prevención de riesgos laborales, como de la psicóloga de este mismo Centro en una reunión de trabajo mantenida con ambos:

La motivación cambiaría si los trabajadores supiesen que pueden promocionar y pasar a otra categoría por esfuerzo personal o por formación. No todos iban a promocionar, pero algunos que podrían dar el perfil para pasar a empre- sa ordinaria y no lo hacen por miedo, podrían permanecer en el Centro especial de empleo habiendo promocionado. Esto en la práctica no puede producirse porque no existe la promoción en el Convenio. Sólo la empresa, a nivel particular, aumenta el salario y las competencias. El Convenio ${ }^{11}$, hoy por hoy, es limitante. Habría que empezar por cambiarlo».

Una encargada del centro especial de empleo de manipulados manifestó algunas afirmaciones muy críticas, que apuntan lugares comunes de distintos testimonios, en ese mismo sentido antes señalado:

La gente aquí no da todas sus capacidades, porque no podemos. He visto a gente que ha querido hacer una cosa, pero no le han dejado, porque no hay tiempo o porque no interesa, $y$ eso desmotiva y quita el derecho de la gente a aprender. El paso a empresa ordinaria es posible con ayuda. Aquí estamos protegidos, pero con ayuda, formación y preparación previa ¿por qué no? Con apoyo, muchos trabajadores de aquí podrían dar el paso a ordinaria, pero el stop está en las familias. Los compañeros no se quejan porque tienen miedo de perder el trabajo. La familia les dice: «tú, a callar».

Volvamos, como apunte final, sobre la reflexión realizada por Castillo y López Calle (2007) que invita a incluir la organización del trabajo como importante factor de riesgo laboral: lo que hemos visto y lo que hemos dialogado en torno al trabajo y a la prevención de riesgos entre los/as trabajadores con discapacidad intelectual confirma de forma rotunda esa incidencia. A partir de esta constatación, efectivamente habría que «ir a las causas del accidente y no sólo a las causas y consecuencias del daño». Si «la actual Ley de prevención de riesgos laborales debe su falta de aplicación real en determinados sectores, y su ineficacia en otros, al tipo de organización del trabajo que los caracteriza» tendremos que derivar, también, que es preciso intervenir sobre esa organización, sobre las concretas condiciones de trabajo, antes que aludir, como problema (culpabilización de la víctima), al trabajador como sujeto-objeto de intervención.

${ }^{11}$ El Convenio a que se refiere, hoy todavía vigente, es el XII Convenio Colectivo General de Centros y Servicios de Atención a Personas con Discapacidad (BOE de 27 de junio de 2006). 


\section{Algunas conclusiones}

En los últimos años, se ha producido una evolución sin precedentes en muy diversos aspectos relacionados con la discapacidad, desde su definición y su concepción actuales a todo un desarrollo normativo y legislativo universal, en cuanto a reconocimiento de derechos en pie de igualdad. La acción positiva emerge con fuerza como propuesta para aportar soluciones y los medios de comunicación, la publicidad y las corrientes asociativas apuntan referencias expresadas de una u otra forma en torno a un mismo slogan: «nosotros podemos». Lamentablemente - como también constata el trabajo presentado - la realidad viene a desmontar los argumentos de ese mundo ideal. El desarrollo normativo no es suficiente para alcanzar las metas de «normalización» para las personas con discapacidad en entornos como el laboral si no se acompaña de un desarrollo organizativo que lo ejecute y de un replanteamiento de los espacios reales de ejecución de esa supuesta integración (¿qué puestos de trabajo?, ¿en qué condiciones?, ¿existe participación de las personas afectadas en las decisiones que les afectan?). Las causas son múltiples y de diversa índole. Una de ellas, la ausencia de formación y cualificación profesionales, se podría modificar estableciendo apoyos y estrategias de fomento de habilidades funcionales, no sólo en la edad laboral sino también desde las etapas iniciales de la vida, que garanticen el mayor grado de autonomía.

La orientación laboral está ausente en el acceso de la mayoría de las personas con discapacidad a un amplio sector del mercado de trabajo. Los encargados y responsables de selección de estos centros han descrito al trabajador con discapacidad intelectual como una persona que accede al mundo laboral sin educación para el trabajo, inmersa en una inercia de sobreprotección, pero con fuerte deseo de mayor autonomía y cuya motivación fundamental para trabajar es económica, sin minimizar aspectos de realización personal y establecimiento de redes y relaciones sociales.

En los centros especiales de empleo en los que se ha realizado este trabajo, es muy común que los trabajadores no posean instrucción previa al desempeño de sus trabajos en sectores como la limpieza, el área de manipulados y artes gráficas y el sector de preparación, envasado de comidas y servicio de catering; sólo en el área de jardinería, los trabajadores entrevistados sí aportaban algún curso de jardinería de mayor o menor duración antes de la incorporación al centro especial de empleo.

La revisión de la literatura y lo observado en el trabajo de campo han puesto de manifiesto un hecho relevante: el trabajador con discapacidad intelectual muestra unas características (resistencia a la monotonía, responsabilidad, meticulosidad, compromiso con la tarea, empatía con los jefes, condescendencia, etc.) que derivan, con los apoyos necesarios, en un elevado rendimiento profesional, por encima de lo generalmente esperado. Este hecho ha sido valorado no sólo por los profesionales que trabajan con este colectivo a diario, sino por los responsables de las empresas clientes que, en contra de prejuicios iniciales, ponderan un trabajo bien hecho.

Relacionado con la escasez de formación profesional de las personas con discapacidad intelectual, la formación en prevención de riesgos laborales se encuentra en un estado deficitario, lo que significa que no ha seguido una evolución acorde con lo establecido en la Ley 31/1995, de prevención de riesgos laborales y con el convenio colectivo del sector. Éste señala, en su art. 85, que dentro de los planes formativos de las empresas se impartirá a cada uno de los/as trabajadores una formación teórica y práctica de 15 horas como mínimo. Hasta la fecha de realización de este estudio ( $\sin$ perjuicio de la puesta en marcha de programas de formación actuales), la formación en riesgos laborales consiste, de forma dominante, en la entrega de unos manuales editados por FEAPS, adaptados para personas con discapacidad intelectual («lectura fácil»). Dichos manuales en la actualidad describen los riesgos laborales de las áreas de jardinería, manipulados y máquinas y limpieza. La entrega la realizan los encargados de los Centros; algunos constatan que se han leído, otros no.

Los trabajadores con discapacidad intelectual entrevistados carecen o tienen muy escasa percepción de riesgo en sus tareas. Conocen algunos riesgos laborales de sus respectivos trabajos, la forma de evitarlos y el empleo de medidas preventivas, como los equipos de protección individual (aunque no sean constantes en su empleo). Muchos aseguran que los riesgos de su trabajo son muy escasos y que la formación específica en riesgos laborales sería 
conveniente, aunque no necesaria. En coherencia con estas percepciones, muestran indiferencia ante la formación en prevención de riesgos laborales. Sin embargo, consideran sus tareas en muchos casos como «simples» y demandan unos contenidos laborales más creativos y que tengan más en cuenta sus capacidades e identifican, aunque no los reconozcan como riesgos laborales, la monotonía y la falta de iniciativa en sus condiciones de trabajo.

Los encargados de estos trabajadores manifiestan que la lectura del manual de FEAPS y las instrucciones recibidas en la propia práctica laboral, en el día a día, son la mejor forma de aprender a realizar su trabajo de forma correcta. Sólo en el centro especial de empleo dedicado a la preparación y envasado de comidas y servicio de catering se ha impartido un curso de prevención de riesgos laborales al personal con discapacidad y otro vinculado al hecho de ser «manipuladores de alimentos» (dirigido, por tanto, a la protección del consumidor, antes que a la propia de los trabajadores). Varios trabajadores del Centro (con y sin discapacidad) consideran que la asimilación de los contenidos del curso no fue la deseada, por no haber sido impartido en un formato adaptado a personas con discapacidad intelectual.

Para terminar, recordemos que en nuestro país se han desarrollado varios Programas para formación en prevención de riesgos laborales para personas con discapacidad intelectual, sin embargo no hemos encontrado después de una búsqueda sistemática el análisis de sus resultados y aplicaciones directas en los centros de trabajo.

Parece que no existe consenso en cuanto al modo más acertado de formar e informar a los trabajadores con discapacidad intelectual en sus riesgos laborales. Es obvia la limitación de la formación existente (escasa e inespecífica), que según muchos trabajadores, va en consonancia con la pobreza de contenidos y tareas (en puestos de trabajo poco exigentes, y poco capacitadores). De manera que demandar una mayor formación, iría aparejada a su vez, de la demanda de unos ámbitos más enriquecedores en los que aplicar dichos conocimientos. Por otro lado, en algunos casos de enclaves laborales, es la propia dirección del centro de trabajo la que impide la correcta forma de actuar, bien por limitar el acceso a recursos preventivos, bien por no facilitar los medios para su empleo.

La línea de futuros trabajos iría encaminada a coordinar la diversidad de enfoques necesarios y, a la vez, adaptados y capacitadores, para asumir las responsabilidades de cuantos intervienen en el ámbito laboral de las personas con discapacidad para, de este modo, hacer realidad el propósito de normalización laboral.

\section{Referencias bibliográficas}

Alonso Seco, J. M. et al. (1997). Realizaciones sobre discapacidad en España. Balance de 20 años. Madrid: Real Patronato de Prevención y de Atención a las Personas con Minusvalía.

Castillo, J.J. y López Calle, P. (2007). La salud laboral en España hoy: analizar las causas complejas, para proponer políticas adecuadas. Sociología del Trabajo, 60, 149-180.

Castillo, J.J. y López Calle, P. (2007). La constitución del moderno sistema nacional de prevención en España. Sociología del Trabajo, 60, 113-148.

Colectivo IOE (1998). Discapacidad y trabajo en España. Estudio de los procesos de inclusión y exclusión social de las personas con discapacidad. Madrid: IMSERSO-Ministerio de Trabajo y Asuntos Sociales.

Colectivo IOÈ (2003). La inserción social de las personas con discapacidades. Madrid: Fundación La Caixa.

Corral Martín, E. R. del. (2004). Prevención de riesgos laborales para la adaptación de trabajadores con discapacidad. (Trabajo Posgrado inédito), Universidad de Sevilla.

Fundación MAPFRE Medicina (1992). Integración Sociolaboral de las personas con minusvalía. Actas del Seminario Europeo EASE-AEDES.

Fundación ONCE (2004) Seguridad y Salud en el Trabajo para las Personas con discapacidad. Prevención y Discapacidad (formato CD), Madrid.

Monnerot, J. (1952). Les faits sociaux ne sont pas de choses. París: Gallimard.

OMS (2001). Clasificación Internacional del Funcionamiento, la Discapacidad y la Salud. Ginebra: Organización Mundial de la Salud. 